\title{
Traditional Hawaiian Healing and Western Influence
}

\author{
Kathryn Hilgenkamp ${ }^{1}$ and Colleen Pescaia ${ }^{2}$ \\ ${ }^{1}$ Waccamaw Mental Health \\ ${ }^{2}$ University of Northern Colorado
}

\begin{abstract}
A significant number of Native Hawaiians have serious health problems related to westernization.On the islands, traditional medical practices and health promotion activities incorporate Hawai'ian healing practices so that strategies are more culturally acceptable An overview of Hawai'ian beliefs regarding health and illness is provided. A description of Hawai'ian healers and their practices provides the most indepth explanation published. Native plants used for healing are also describes. The need for Hawai'ians to be actively involved in their own health care is emphasized.
\end{abstract}

(c) 2003 Californian Journal of Health Promotion. All rights reserved.

Keywords: healing, Hawaiian, folk medicine

The latest U. S. Census estimated that 368,600 Native and part blood Hawaiians were living in the state of Hawaii (Hawai'i State Department of Business, Economic Development, and Tourism, 2000). It is estimated that only 6,000-8,000 are pure Hawaiian. Native Hawaiians constitute a significant proportion of the Hawaii's poor and unemployed. They are also more likely to have serious health problems. Such as cancer, alcohol abuse, tobacco abuse, diabetes, and other health problems. Native Hawaiians have higher mortality rates for every major cause of death than the general population (Pinkney, 1990). Life expectancy for Native Hawaiians is currently the lowest in the United States, estimated at 74.3 years (Hawai'i State Department of Health, 2000a). Heart disease mortality rates for Native Hawaiians are 44\% higher for both men and women. Cancer rates are $39 \%$ higher, and cerebrovascular rates are $31 \%$ higher than U. S. national averages (Mokuau, 1990; Mokuau, Hughes, \& Tsark, 1995; Chang, 2001). The prevalence rate for obesity is $64 \%$ compared to $26 \%$ for the U. S. The smoking rate is $32 \%$ compared to the U. S. rate of 29\% (Chang, 2001). Hawaiian infant mortality rates during 1999 were the second highest in the nation, reaching an estimated 7.5 per 1,000 births (Hawai'i State Department of Health, 2000b). These poor rates are attributed to the Hawaiian genotype, the adoption of a "modern, industrialized lifestyle" with poor diet and exercise habits, and lack of health care accessibility due to geographic location.

Many consider the conflict between western medicine and traditional Hawaiian healing practices to be part of the problem. When Hawaiians return to their traditional diet, chronic diseases change dramatically (Batchelder, 2001). Today there are a limited number of traditional healers practicing in the state of Hawaii, and few practitioners that understand culturally appropriate healing strategies that can be used in Western medicine practices. Many Hawaiians distrust and refuse Western medical practices today.

Until the arrival of Westerners onto the Islands of Hawaii, the people lived in a thriving and nourishing environment. Very few people became ill. They followed a kapu system enabling them to prosper and live peacefully with nature (Oneha, 2001). Few people became ill. In the 1700s, the Pacific Islands were invaded by Europeans who brought diseases such as smallpox to the natives, killing many (Judd, 1998). When Captain Cook arrived, there were approximately 800,000 Native Hawaiians, but by the early 1800 's, they were reduced to 
180,000 (Mokuau, 1990). The caste system was abolished. Because Hawaiian culture yielded to western culture, the art of Hawaiian healing diminished greatly (McBride, 1975). Hawaiian medical practices have deteriorated and have become fragmented. An understanding of Hawaiian healing philosophy is essential to build trust and acceptance of western medicine in the islands and honor Hawaiian values.

\section{Hawaiian Values}

The Hawaiian word for health is ola (life). Without health, there is no life. Hawaiians view the body, mind, and spirit as one. The body can not be healed without healing the spirit. Hawaiian culture considers nature and health to be entwined. Many Hawaiians believed that when a person became ill, it was punishment for breaking rules or participating in some form of evil act. When the environment is affected in a positive or negative way, everything is affected (Oneha, 2001). Ka mauli o k'aina a he mauli kanasa is a Hawaiian expression defining the belief that maintaining the aina (land) promotes the health of the people. Native Hawaiians believe that the land, trees, ocean, and winds all impact their body, mind, and spirit through mana, the healing energy felt by the soul from the Islands (Kahlewai, 2000). It is believed that all things in nature are interrelated by a creative power from the gods (Mokuau, 1990).

Traditional healing for Native Hawaiians has an environmental philosophy known as lokahi. Lokahi refers to harmony between man, nature, and the gods. Hawaiians believe it is important to keep peace with the self, the family, the gods, and the land in order to live a prosperous life (Mokuau, 1990). The resulting feeling of wholeness is known as ho'omana. Without lokahi, there is illness.

\section{Kahunas}

Hawaiian healers are known as kahunas. The kahuna is a priest or teacher. At one time, training occurred from heiau (healing temples). A kahuna is very secretive about the treatments and cures. The term means "keeper of the secret." Most kahunas only treat members of their family. The family often calls the kahuna 'papa' or 'uncle." Kahunas are chosen within the family and entrusted to preserve the knowledge and history of Hawaiian healing. If a parent sensed a child had a "healing spirit," they sent them to live and study with a kahuna from as young as five years of age. They would spend fifteen to twenty years studying anatomy, diagnostics, herbs, treatments (steam baths, massage, laxatives, etc.), simple surgical procedures, set bones, and sacred prayers.

There are several different types of kahunas. Kahuna haihai iwi set broken bones. Kahuna haha diagnose illnesses by feeling with the fingers. Kahuna hoohanau keiki deliver babies and provide pale keki for the mother and child before, during, and after birth. Kahuna paaoao diagnose and treat illnesses of infants. Kahuna lomilomi are physical therapists skilled in massage. Kahuna aloha specialize in inducing love. The kahuna la'au lapa'au, or herbalist, administers Hawaiian healing herbs.

\section{Huna}

Huna practitioners believe the teachings are ancient and sacred, being secretive about treatments and cures. Huna is only passed from one kahuna to another. The word huna means "secret" or "that which is hidden" (Helwig, 2003). Huna was outlawed in the 19th century by Christian missionaries in the Hawaiian Islands. It was passed on through oral communication and chants rather than in writing. Huna is a type of psychology used to use the powers of the mind to accomplish healing and spiritual development. Huna begins with the understanding of the ten elements of self and learning to "talk to self." The ten elements consist of three selves, three invisible bodies of each self, three voltages of energy, and the physical body. The three selves consist of the high self (aumakua or superconscious), middle self (uhane or conscious), and the low self (unihipili or subconscious). The bodies of the self vary in density controlling the supply of energy to the other selves. The low self supplies mana (energy) to the physical body. The low self also converts mana to mana-mana (higher voltage) to be used by the middle self. The middle self uses mana to think and feel and emerges as one's personality. The low self and middle self supply mana to the high self. The 
high self converts mana to mana-loa (the healing force). The high self is the person's divine connection with God. Communication between the three selves is important. Blockages are caused by fear, anger, or negative programming.

Huna is said to benefit the person by becoming complete. It enables the person to solve personal problems, have a higher level of energy so they can meet the demands and stresses of daily life more effectively. The energy helps attain personal goals. It help the person health oneself and others. It is also said to help the person grow spiritually, changing one's future. The kahuna removes the blocks using telepathy, rituals, massage, body stroking, herbs, dream work, meditative movements and other selfdevelopment techniques to establish harmony among people, objects, locations, and circumstances. The kahuna prays using wai-pa (to divide the waters) to send mana to the three selves and an offering to the high self making a request. The emphasis is on creating an energy field to re-establish harmony and balance between the three selves.

\section{Hawaiian Healing Practices Today}

It is estimated that there are 14 different healing practices among Hawaiians (Pinkney, 1990). Some of the practices such as acupuncture, shiatsu, tai chi, and herbal medicine are from the Chinese and Japanese who migrated to Hawaii. In a study investigating the use of Hawaiian healing practices, Chang (2001) interviewed 25 Hawaiian health practitioners on the island of O'ahu. The practitioners using Hawaiian healing techniques apprenticed under one or more master healers or a recognized elder healer, often a family member. Prior to and after administering a healing modality, spiritual blessings were administered. The three modalities that were primarily used were: ho'olomilomi, la'au lapa'au, and ho'opononpono.

\section{Ho'olomilomi}

Ho'olomilomi is the practice of massage. Lomilomi means "to break up into small pieces with the fingers." This form of massage has physical and spiritual rituals. Lomilomi has been used for childbirth, congestion, inflammation, rheumatism, asthma, and bronchitis. Lomilomi is used on babies and children to mold their features for beauty and strengthen them. Each family had a kahuna specializing in lomilomi massage, trained by the village kahuna. The family member would pass on the technique to the next generation. The person to be healed lies on a table with a healing state of mind. The technique begins by using heated lomi stones to increase blood flow to certain areas of the body. The massage touch is similar to the Swedish massage technique, stroking out and away from the body, but using elbows and forearms with deep tissue techniques. This technique is referred to as "loving hands." Lomilomi cleanses and relaxes the body, increasing circulation, and relieving pain. The lomilomi kahuna also transferred positive thoughts channeling mana (life force or energy) to release a sense of wellbeing.

\section{La'au lapa'au}

La'au lapa'au is an herbalist healing practice passed down from generation to generation and is practiced by kahunas (Judd, 1998). The practice of lapa'au includes the use of plants, animals, and mineral products from the ocean and the land (Chang, 2001). Many lush tropical plants on the Hawaiian islands have healing properties. It is estimated that over 300 plants have been used since the beginning of lapa'au (Norton, 1998). Unfortunately, deforestation, urban sprawl, and expansion on the islands has caused many plants to be eliminated or extinct so there are only 30 plants used, and only 16 of those plants are easy to find and readily available (Horowitz, 2001; Norton, 1998). The kahuna gathers, prepares, and administers the herbs according to the needs of the patient and healing properties. The stems, flowers, leaves, roots, seeds, bark, and resins are all used in the form of a tea, extract, juice, or wrapped in coconut leaves called nui fronds (Krauss, 2001). After gathering the herbs, a pule (prayer) would be said to incorporate spiritual healing through the body, mind, and spirit (Chang, 2001; Horrigan, 2000).

Many of the plants used for healing have exceptional healing properties and have become 
accepted in Western medicine. More wellknown botanicals include aloe vera, awa, awapuhi, kalo, ko, mai'a, noni, and olena. Aloe vera is used for burns, high blood pressure, diabetes, and cancer. Ava, also known as kava, must be consumed according to specific rules. Kava is used for problems such as anxiety and insomnia. Awapuhi is ginger. The root is used to treat ringworm, sprains, bruises, headache, toothache, and stomach ache. Ginger root is used for an upset stomach. Kalo is taro, the most important plant in Hawaiian culture. The root is rubbed on wounds to stop bleeding and prevent swelling of bites and stings. The leaves are used to treat asthma and the corms are used to treat indigestion and constipation. Ko'oko'olau or ki nehe is brewed into a tea for tuberculosis and other chronic diseases. The flower bud from mai'a or banana is used for nervousness in children. The sap from a stalk is used for chest pain, the corms for tuberculosis. Noni or Indian Mulberry has been used for many things, such as kidney problems, high blood pressure, diabetes, loss of appetite, muscle and joint pain, as a blood cleansing agent, immune booster, and cancer preventative. Betel nut palm is used to boost energy and delay fatigue. Olena or tumeric is mashed and the juice is used as a blood purifier.

Laukahi or Plantain leaves are used for diabetes, helping regulate blood sugar levels. The seed husks are dried and used for constipation. Pohuehue or Beach Morning Glory taproots are mashed and made into a drink for skin infections and inflammation. Hala or Screw Pine root tips are used for chest pain and muscle tightness. Popolo or Glossy Nightshade berries, bark and leaves are used for asthma. Ulu or Breadfruit is used to make a tea to treat diabetes and high blood pressure. The research and use of Hawaiian botanicals is gaining in popularity today. Researchers have found that four plants, kipiko, naupaka, mamaki, and ohia'ai have antiviral properties (Locher et al., 1995). Kopiko bark and leaves are used to heal cuts and wounds. Mamaki bark, leaves, and stems are used for general debility, expectant mothers, blood purification, and as a laxative. Ohia'ai or Mountain Apple leaves and bark are used to treat general debility, sore throats, cuts, thrush, venereal disease, tuberculosis, and digestive tract disorders. Another herb, kukui or Candlenut Tree (the Hawaiian state tree) has an anti-bacterial effect and is useful for preventing $S$. aureus and P. aeruginosa.

\section{Ho'opononpono}

Ho'opononpono (make things right or "problem solving") refers to counseling and mediation to resolve conflicts and balance relationships (Helwig, 2003). Ho’opononpono can be used for an individual or a group of individuals. For individuals, the object is to heal a person by removing obstacles to being well. The obstacle may be low self-esteem, sadness, guilt, or the inability to forgive oneself for something they have done in the past. For a group conflict, the kahuna allows everyone to speak until all resentments and other feelings come out. No one is permitted to leave the room. Eventually, the resolution comes and the session is concluded. The session may include prayer to cleanse the mind and heart of negative thoughts and feelings.

The kahuna may also use kalana hula for meditative movements in an effort to restore harmony. Breathing techniques are used to increase a person's mana. The basic breathing technique draws in a deep breath, holding it, and willing the mana into a body part that needs healing, the hands, or an object like a crystal or talisman. The emphasis is on living and speaking positively, doing no harm to others, and being of service to others to promote general wellness.

\section{Implications}

The knowledge of Hawaiian healing practices has been integrated with Western medicine for the development of preventive health programs and treatment plans of Hawaiian people. The Native Hawaiian Health Care Act of 1988 recognized the use of traditional healers as a way to improve the health status of native islanders. Ho'oponopono is practiced in health care centers serving Native Hawaiians. On the Waianae Coast of Oahu where most of the Native descendants live, Hawaiian healing medicine is the treatment of choice. The environment offered by a healer is preferred to 
the cold and impersonal atmosphere of a physician's office or hospital. Hospitals encourage the spirit of aloha, the philosophy of lokomaika'i (inner health), and family-centered care. The physical, spiritual, and emotional health of patients and employees is also encouraged. Queens' Medical Center in Honolulu also provides a healing garden and Hawaiian healing therapies (Walker \& Irvine, 1997).

There are approximately 60-80 kahunas in Hawaii with the average age of 75 (Pinkney, 1990). Kahunas today are allowed to practice openly and are integrated into the health care system. Kahunas do not consider themselves substitutes for Western-trained physicians. They do not claim to cure people. Most of the treatments are considered harmless. Kahunas develop strong interpersonal relationships with the patient. They take all the time they need with the patient, giving love and positive spirit. Most Natives believe that when a kahuna arrives, they will get better. They ask the patient to look within themselves in order to heal themselves. The positive atmosphere provided by the kahuna empowers the patient, facilitating the healing process. Kahunas never ask for payment and are usually paid with offerings such as eggs, chickens, bananas, or whatever the patient and family have to offer.

An organization known as E Ola Mau, which means "to live on" consists of health care providers of native Hawaiian descent trained in either Western or Hawaiian healing. The membership includes physicians, nurses, dentists, massage therapists, and herbal specialists. The use of translators while treating Hawaiian clients, the use of traditional healers to develop preventive health programs, the training of health practitioners in the art and science of Hawaiian healing practices, and allowing Hawaiian healers to help patients are just some of the ways Western medical practices can be enhanced for Hawaiians.

\section{Summary}

Traditional Hawaiian healing practices are important to the health of Hawaiians. The Hawaiian people should be able to nurture their culture and have an active role in planning their plan of treatment and prevention programs. Health care professionals, public health planners, and health educators need to learn more about Hawaiian culture and healing practices in order to become culturally competent. Preserving the cultural heritage of clients improves the integrity of our profession and of our methods. By learning more about a culture based solely on the love of life in harmony with nature, we can do more to help ourselves. By sharing the philosophy and practices with others, we can help them lead healthier lives. Increased interest in and use of complementary and alternative medical therapies reveals that Americans are eager to learn self-care and preventive strategies from other cultures. What is learned by studying Hawaiian healing practices can create understanding and prove valuable in helping individuals stay and get well.

\section{References}

Batchelder, T. (2001). Medical anthropology: Medical ethnobotanicals of the Hawaiian Islands. Townsend Letter for Doctors and Patients. Retrieved October 13, 2003, from http://www.findarticles.com/cf_0/mOISW/2001_August/78177233/print.jhtml

Chang, H. K. (2001). Hawaiian health practitioners in contemporary society. Pacific Health Dialog, 8(2), 260-273.

Davidson, T. (2003). Lomilomi. Gale Encyclopedia of Alternative Medicine. Retrieved October 13, 2003, from http://www.findarticles.com/cf-)/2603/000/2603000079/pl/article.jhtml?term=Hawaii.

Hawai'i State Department of Business, Economic Development, and Tourism. (2000). The State of Hawai'i data book: A statistical abstract. Retrieved October 13, 2003, from http://www.healthtrends.org/health status/lifeexpect.html

Hawai'i State Department of Health. (2000a). Health surveillance program. Retrieved October 13, 2003, from http://www.healthtrends.org/demographics/ethnic distrib.html\#1 
Hawai'i State Department of Health. (2000b). Vital statistics records. Retrieved October 13, 2003, from http://www.healthtrends.org/health status/infant/ethnicity.html

Helwig, D. (2003). Huna. Retrieved October 13, 2003, from http://www.findarticles.com/cf_0/g2603/0004/2603000436/print.jhtml

Horowitz, S. (2001). Traditional Hawaiian healing arts enrich conventional medical practices. Alternative \& Complementary Therapies, 7(2), 68-73.

Horrigan, B. (2000). Papa Henry auwae po'okela la'au lapa'au: Master of Hawaiian medicine. Alternative Therapies, 6(10), 83-88.

Judd, N. (1998). Laau lapaau: Herbal healing among contemporary Hawai’ian healers. Pacific Health Journal, 5(2), 239-245.

Kahalewai, N. S. (2000). Hawaiian lomilomi Big Island massage. Mt. View, HI: Island Massage Publishing.

Krauss, B. (2001). Plants in Hawaiian medicine. Honolulu, HI: The Bess Press.

Krauss, B. (1993). Plants in Hawaiian culture. Honolulu, HI: University of Hawaii Press.

Locher, C. P., Burch, M. T., Mower, H. F., Berestecky, J., Davis, H., Van Poel, B., et al. (1995). Antimicrobial activity and anti-complement activity of extracts obtained from selected Hawaiian medicinal plants. Journal of Ethnopharmacology, 49, 23-32.

McBride, L. R. (1975). Practical folk medicine of Hawaii. Hilo, HI: Petroglyph Press.

Mokuau, N. (1990). The impoverishment of native Hawaiians and the social work challenge. Health \& Social Work, 15(3), 235-243.

Mokuau, N., Hughes, C. K., \& Tsark, J. U. (1995). Heart disease and associated risk factors among Hawaiians: Culturally responsive strategies. Health \& Social Work, 20(10), 46-51.

Norton, S. A. (1998). Herbal medicines in Hawaii from tradition to convention. Hawaii Medical Journal, 57(1), 382-386.

Oneha, M. F. M. (2001). Ka mauli o ka 'aina a he mauli kananka: An ethnographic study from a Hawaiian sense of place. Pacific Health Dialogue, 8(2), 299-311.

Pinkney, D. S. (1990). Native healers: Sharing the cures and hopes of traditional Hawaiian medicine. American Medical News, 33(4), 9-11.

Walker, D. D., \& Irvine, N. P. (1997). Lokomaika’I in a remarkable hospital. Nursing Management, 28(6), 33-37.

\title{
Additional Resources
}

Aloha International, P. O. Box 665, Kilauea, HI 96754. Ph. 808-828-0302. URL: http://www.huna.org Huna Research, Inc., 1760 Anna Street, Cape Girardeau, MO 63701-4504. Ph. 573-334-3478

Mala Laau: A Garden of Hawaiian Healing Plants. Hawaii Medical Library, 221 Punchbowl Street, Honolulu, HI.

\author{
Author Information \\ Kathryn Hilgenkamp, Ed. D.*, Couselor \\ Waccamaw Center for Mental Health \\ Conway, SC 29528 \\ E-mail: khilgenkamp@sc.rr.com \\ Phone: 843-234-2900 \\ Colleen Pescaia, M.P.H. Student \\ University of Northern California \\ * corresponding author
}

